\title{
New Boundaries, New Uncertainties: COVID-19 as both Barrier and Gateway to Engagement with Online Mental Health Train- ing and Support
}

\author{
Trisha Forbes ${ }^{1}$, Karen Galway ${ }^{1}$, Paul Best ${ }^{1}$, Heike Schroder ${ }^{2}$, Paula McFadden ${ }^{3}$, Patricia Gillen ${ }^{4}$, Mark Tully ${ }^{3}$, \\ John Moriarty ${ }^{5, *}$
}

Publisher's Note: MDPI stays neutral with regard to jurisdictional claims in published maps and institutional affiliations.

\section{(c) (i)}

Copyright: (C) 2021 by the authors. Submitted for possible open access publication under the terms and conditions of the Creative Commons Attribution (CC BY) license (http://creativecommons.org/licenses/by/4.0/).

\author{
Centre for Evidence and Social Innovation, Queen's University Belfast \\ Queen's Management School, Queen's University Belfast \\ Ulster University \\ Ulster University, Southern Health and Social Care Trust, Northern Ireland \\ Centre for Evidence and Social Innovation, Queen's University Belfast \\ Correspondence: j.moriarty@qub.ac.uk
}

\begin{abstract}
Introduction As well as being a common source of stress, the workplace can be an arena in which greater awareness of the nature and causes of mental ill-health can be fostered. The COVID19 pandemic has changed the nature of work and the context of occupational health. iAmAWARE is an online platform, which enables employees to access psychoeducation and stress reduction training. Piloting of iAmAWARE with participant organisations coincided with the beginning of COVID lockdown. This paper reflects on lessons learned from introducing iAmAWARE and considers how participants reported the impact of lockdown on their personal wellbeing. Methods Following prior consultation and design input from representatives of the organisations, a prototype

of iAmAWARE was made available to participants, with surveys before and after the period capturing wellbeing, workplace stress and mental health literacy. Results COVID-19 presents major challenges for both researchers and organisations wishing to positively impact employees' mental health. The participation of organisations and employees was put under strain by uncertainty and demands of responding to lockdown conditions. Our study demonstrates growing levels of engagement with mental health, suggesting demand for programmes which are demonstrably effective and adaptable to shifting organisational contexts. Conclusions Employers are correct to view COVID as a moment to invest in employees' mental wellbeing and allow employees time to upskill and increase awareness. Researchers must be flexible, adaptable and sensitive to the needs of organisations if they wish to produce research which impacts workplace wellbeing.
\end{abstract}

Keywords: mental health; workplaces; wellbeing; computer-based; online; psychoeducation; coproduction; occupational health; covid-19

\section{Introduction}

One of the immediate impacts of the COVID-19 pandemic has been on the nature of work. With people working in new locations, often their homes, with new technologies, new practices and within adapted working patterns and rhythms, the context in which we consider occupational health and mental wellbeing is utterly changed. While organisations have sought to protect viability and job security of employees in the short-term, large questions remain about the quality of work and working lives people will have in the future, particularly in a less socially interactive work paradigm [1,2]. 
Online mental health training platforms have significant potential as an efficient means of improving mental wellbeing in the working population [3,4]. With remote working presenting new challenges for maintaining and supporting wellbeing, and with inperson training impeded by social distancing requirements, demand for evidence based online training may increase in the near future. The iAmAWARE project began in 2019 with the aim of working with employees in a participating organisation to co-produce and pilot a platform which would be interactive, informative and of direct relevant to the management of workplace stressors. Having gathered employee input through focus groups on challenges to mental health faced in their context and their expectations for online training, a prototype of iAmAWARE was made available to employees of one participating organisation between March and May of 2020. The scheduled roll-out of the trial programme transpired to coincide with the United Kingdom's response to rising COVID-19 case rates and the attendant restrictions on movement. This presented a challenge to the successful delivery of the programme across that organisation, but also an opportunity to understand the impact of the early phase of the pandemic.

\section{Methods}

Participants were surveyed about their levels of mental wellbeing and their knowledge of mental health before and after the period in which the iAmAWARE programme was available to them. In the context of the post-intervention survey administered between May and June of 2020, participants were asked four questions specifically relating to the impact of COVID [1].

\begin{tabular}{|c|c|}
\hline Question & Responses $(N=71)$ \\
\hline $\begin{array}{c}\text { "Do you feel that the COVID-19 lockdown has impacted on your mental } \\
\text { health?" }\end{array}$ & $\begin{array}{c}\text { Yes - } 51 \\
\text { No - } 9 \\
\text { Unsure }-11\end{array}$ \\
\hline "Please explain your answer to (the preceding question)" & Open Text \\
\hline $\begin{array}{l}\text { "Do you feel that anything you learned as part of the iAmAWARE platform } \\
\text { has helped you to cope better during lockdown?" }\end{array}$ & $\begin{array}{c}\text { Yes }-40 \\
\text { No }-8 \\
\text { Maybe }-14 \\
\text { Did not engage }-9\end{array}$ \\
\hline "Please explain your answer to (the preceding question)" & Open Text \\
\hline
\end{tabular}

In this paper, we focus on a preliminary thematic analysis of the open text responses provided by employees [5]. Responses were coded and organised independently by three researchers and then discussed. It was agreed that the principal point of contrast among responses to was between respondents interpreting the impacts on mental health as having a negative toll on mental health, while a notable number of their colleagues saw the impact as positive in the main. For this analysis, we identify various ways in which these positive and negative experiences were described.

\section{Results}

Approximately 200 employees were offered the opportunity to complete iAmAware in the focal organisation. Whereas the pre-programme survey received 126 responses, the post-programme response was 71 . This suggests an above-average attrition rate within a short period and raises concerns as to the representativeness of those providing sufficient data for a pre-and-post comparison.

Responses reflected diverse experiences of the pandemic and lockdown. In the main, responses tended to have a single 'valence', primarily emphasising either adverse impacts, salient benefits, or a neutral non-impact. Only a relatively small subset of responses captured a mix of positive and negative experiences: 
"In some ways it has benefitted my mental health e.g. I have the time and freedom to have a break for meditation/quick exercise that I wouldn't in the office. More time with family/no commute benefits how I feel too. However, there is increased anxiety about the future, job security and the potential return to the office which has a negative impact."

Listed separately, this respondent's observations are broadly representative, though the response itself is unusual in being 'net neutral' through weighing up commensurate costs and benefits to wellbeing.

\subsection{Types of negative experience}

\subsubsection{Anxiety and worry}

People expressed worry about a range of subjects related to the pandemic. For some, the threat of the virus itself was a source of concern, while the impact of lockdown was more salient for others.

"At times the uncertainty around covid-19 has impacted my mood. This has only been for brief periods (usually a few hours or a day) but I feel that in general I have been more stressed and felt a higher level of anxiety throughout the past few months."

"Isolation, Separation from family, stress from cancelling a wedding, financial worry from a furloughed partner, worry of sickness and death within vulnerable family."

Often life-stage, personal and familial circumstances shaped the focus of respondents' worries.

"The insolation was unsettling. I missed people and every weekend and day blurred into one. At times I felt caged up and unable to get out."

\subsubsection{Interference with boundaries between home and work}

The spatial dimension of lockdown and the spatial proximity of work and personal spaces was cited as an impact.

"Period of adjustment to having work, family life, and the whims of a 2 year old competing for the same space."

A lack of work-life balance was frequently highlighted. Being at home was sometimes cited as a stressor in that it created additional housework from which there was no ready escape. For some confinement to home stripped the homeplace of its comfort associated with the end of the work day.

"Lack of work and personal separation has made me feel like there is no real break from work. Find it hard to disengage or log off at the correct time."

\subsubsection{Exacerbate long-term mental health problems}

A key focus of iAmAWARE is raising awareness of the distinctions of mental health and wellbeing as experienced by all employees, versus diagnosed mental health conditions. This same distinction was mirrored in responses, with a small number of respondents focusing on the effect of the pandemic on a specific condition, such as depression or social phobia.

"By not having to push myself out and into situations that trigger my anxiety it has made a bigger problem. Going out now, at times, is more difficult than it ever was before."

\subsection{Types of positive experience}

\subsubsection{Preferable routine}


It is notable where participants reflecting on positive outworkings of the pandemic label these explicitly as positive. This may reflect that the dominant public narratives about lockdown have revolved around isolation and other challenges, rendering positive viewpoints counter-cultural.

"In a positive way... I have felt less stressed about travelling to work and have more time at home."

\subsubsection{Opportunity for development, adaptation and growth}

The second question about how iAmAWARE influenced coping during lockdown prompted some broader responses which indicated that the new work arrangements prompted the adoption of new work practices.

"I was able to learn to clock off at the end of every workday and not think about the worries and stresses of work afterwards. I feel that having a routine really helped."

"I am more aware of my feelings and trying to recognise negative feelings and thoughts and trying to do small things to improve my mood and making sure I do not spiral with negative thoughts."

\section{Discussion and Limitations}

COVID-19 presents major challenges for organisations and for their employees. $\mathrm{Nu}$ merically, negative reflections on the experiences from the pandemic were more frequent than positive accounts in the organisation surveyed. These show an augmented function of work with additional demands stresses experienced by many employees while the social interpersonal rewards of the occupation dwindled. Rather than complimenting other facets of life, work came into direct conflict with family and home life. It is possible that more time to reflect on the impact of the pandemic might have rendered more nuanced and neutral responses: by collecting these data in June we capture the immediacy of the threat of virus and of the disruption to normal life. It would also be remiss to overlook that a significant minority of responses cited positive benefits of the pandemic period for some of those who remained healthy throughout the period.

Furthermore, the participation of organisations and employees in the online training programme was put under strain by uncertainty and increased demands associated with working at home while managing a changed personal life. In the longer term though, with the prospect of remote working becoming more common, manageable and acceptable within organisations, programmes such as iAmAWARE could hold significant promise. Feedback suggested many employees had tangible uses for techniques and knowledge accessed through the programme. It is difficult to infer either a true baseline level of wellbeing for employees or disentangle the impact of the programme from that of the volatile environment. Just as the study aimed from the outset to be adaptable to organisational contexts, programme planners aiming to maximise uptake and impact should carefully consider the organisational conditions into which a new programme is being introduced.

\section{Conclusions}

COVID-19 has underscored the importance of the workplace and employment to public policy. Preserving employment has been a key pillar of governmental efforts to minimise economic harm from this "Pandession"[6]. Employers have also played a key role in helping government administer job retention initiatives and pandemic payments. Just so, the workplace can be an arena in which some of the potential long-run harms to mental wellbeing can be tackled head-on. Employers are correct to view COVID-19 as a moment to invest in employees' mental wellbeing and allow employees time to upskill and increase awareness. This is complicated by the fact that work is often central to em- 
ployees narratives of their wellbeing and identity, but a whole-of-organisation commitment to better wellbeing and greater literacy around mental health could help to deliver on this potential.

\section{References}

1. House of Lords Living Online: The Long-Term Impact on Wellbeing: COVID-19 Committee Inquiry. 2020. Available online: https://committees.parliament.uk/work/742/living-online-the-longterm-impact-on-wellbeing

2. Irvine, G. Good Work for Wellbeing in the Coronavirus Economy. Carnegie Trust: Dunfermaline: 2020; ISBN: 978-1-912908-49-3

3. Carolan, S., Harris, P.R., \& Cavanagh, K. Improving employee well-being and effectiveness: systematic review and meta-analysis of web-based psychological interventions delivered in the workplace. Journal of Medical Internet Research 2017, $19(7)$ e271. doi:10.2196/jmir.7583

4. Stratton, E., Lampit, A., Choi, I., Calvo, R.A., Harvey, S.B., \& Glozier, N. Effectiveness of eHealth interventions for reducing mental health conditions in employees: A systematic review and meta-analysis, PLoS One 2017, 12(12): e0189904.

5. Braun, V. \& Clarke, V. Using thematic analysis in psychology. Qualitative Research in Psychology 2006, 3(2), 77-101. doi: 10.1191/1478088706qp063oa

6. McWilliams, D. We are living through a 'Pandession'-here's how we escape. The Irish Times, May 16 ${ }^{\text {th }} 2020$. Available online: https://www.irishtimes.com/opinion/david-mcwilliams-we-are-living-through-a-pandession-here-s-how-we-escape 